\title{
The Effects of Vitamin D on Insulin Release From Isolated Islets of Rats
}

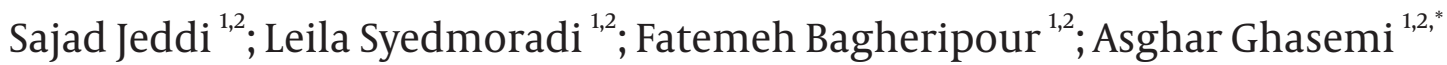 \\ ${ }_{1}^{1}$ Endocrine Physiology Research Center, Research Institute for Endocrine Sciences, Shahid Beheshti University of Medical Sciences, Tehran, IR Iran \\ ${ }^{2}$ Endocrine Research Center, Research Institute for Endocrine Sciences, Shahid Beheshti University of Medical Sciences, Tehran, IR Iran \\ ${ }^{*}$ Corresponding author: Asghar Ghasemi, Endocrine Physiology Research Center, Research Institute for Endocrine Sciences, Shahid Beheshti University of Medical Sciences, P.O. Box: \\ 193954763, Tehran, IR Iran. Tel: +98-2122432500, Fax: +98-2122416264, E-mail: Ghasemi@endocrine.ac.ir
}

Received: May 24, 2014; Revised: August 11, 2014; Accepted: October 19, 2014

\begin{abstract}
Background: Vitamin D (vit D) affects glucose metabolism. Receptors of vitamin D have been identified in cells and studies show that vitamin D deficiency reduces glucose-stimulated insulin secretion (GSIS).

Objectives: The aim of this study was to examine the effect of vitamin D on insulin release from isolated islets of rats.

Materials and Methods: Islets were isolated from male Wistar rats, weighing 200-250 grams, using the collagenase digestion method. Insulin release was assessed following 24 and 48 hours coincubation of islets with vitamin $\mathrm{D}(0.1,1$ and $10 \mathrm{nM})$ and glucose (5.6,11.1 and 16.7 $\mathrm{mM}$ ). In addition, islets were preincubated with vitamin D for 24 and 48 hours and GSIS was assessed for one hour in the presence of 5.6 and $16.7 \mathrm{mM}$ glucose.

Results: Coincubation of islets with vitamin D $(10 \mathrm{nM})$ and $11.1 \mathrm{mM}$ glucose increased islet insulin release $(37.27 \pm 3.75 \mathrm{vs} .24 .64 \pm 2.83 \mathrm{ng} /$ islet/24 hours; $\mathrm{P}<0.05)$, while vitamin $\mathrm{D}(1$ and $10 \mathrm{nM})$ decreased insulin release in the presence of $16.7 \mathrm{mM}$ glucose $(21.14 \pm 3.58$ and $18.65 \pm$ 3.84 vs. $37.71 \pm 4.63 \mathrm{ng} /$ islet/24 hours; $\mathrm{P}<0.05$ ). Islets preincubation with vitamin $\mathrm{D}$ ( 1 and $10 \mathrm{nM}$ ) increased GSIS in the presence of $16.7 \mathrm{mM}$ glucose ( $4.39 \pm 0.73$ and $4.39 \pm 0.63$ vs. $2.07 \pm 0.43$ ng/islet/ 1 hour; $\mathrm{P}<0.05$ ).

Conclusions: Preincubation of islets with vitamin D increased GSIS but decreased insulin release in coincubation with high levels of glucose. Insulin secretion from cells in the presence of glucose seems to be related to the dosage of vitamin D and duration of preincubation.

Keywords:Pancreatic Islets; Rat; Vitamin D; Insulin
\end{abstract}

\section{Background}

Worldwide prevalence of diabetes has been recently increased over two-fold and is estimated to affect 439 million people by the year $2030(1,2)$. Diabetes is a complex metabolic disease characterized by high blood glucose level resulting from defects in insulin secretion or action (2).1, 25-dihydroxyvitamin D3 (vit D), the most potent metabolite of vitamin $\mathrm{D}$, plays an important role in calcium and phosphate homeostasis, also vital for a number of other biological activities including immunomodulation and normal release of insulin from cells (3-5). Pancreatic islets have both vitamin D receptors and vitamin D-dependent calcium-binding proteins, suggesting a role for vitamin $\mathrm{D}$ in insulin secretion $(6,7)$.

It has been reported that vitamin D deficiency impairs insulin synthesis and secretion in both human and animal models and its replenishment improves cell function and glucose tolerance $(4,8,9)$. Cade et al. have shown improvement in glucose metabolism and insulin secretion in vitamin D-deficient rats following a single subcutaneous injection of vitamin $\mathrm{D}(10)$. In addition, it has been reported that de novo insulin synthesis is reduced in isolated islets in vitamin D-deficient rats and insulin biosynthetic capacity can be restored in vitro by injection of vitamin D (9). vitamin $\mathrm{D}$ deficiency may be related to type 2 diabetes, car- diovascular disease and cancer $(11,12)$. Subjects with type 2 diabetes have lower circulating vitamin D levels compared to healthy controls $(3,13)$. Furthermore, epidemiological studies have shown that vitamin $D$ receptor restriction site polymorphisms are associated with genetic susceptibility to type 1 diabetes in different populations, while vitamin D supplementation in early childhood is associated with a reduced risk of type 1 diabetes (14). Nikooyeh et al. have reported that daily consumption of vitamin $\mathrm{D}$ improves glycemic status in patients with type 2 diabetes (15). Interventional studies investigating vitamin $\mathrm{D}$ for treatment of type 2 diabetes have shown negligible effects, and the results available in humans have been contradictory (15).

\section{Objectives}

Previous studies have reported that high glucose concentrations significantly decreased total insulin secretion from cells (16). The effects of coincubation and preincubation of vitamin D with high glucose concentration on insulin secretion from islets have not been fully understood yet. Therefore, the aim of this study was to determine the effects of vitamin D on insulin release from isolated islets of rats.

Copyright (C) 2015, Research Institute For Endocrine Sciences and Iran Endocrine Society. This is an open-access article distributed under the terms of the Creative Commons Attribution-NonCommercial 4.0 International License (http://creativecommons.org/licenses/by-nc/4.0/) which permits copy and redistribute the material just in noncommercial usages, provided the original work is properly cited. 


\section{Materials and Methods}

Adult male Wistar rats (two months old, weighing 200250 grams) were obtained from the laboratory animal house of the Research Institute for Endocrine Sciences, Shahid Beheshti University of Medical Sciences and housed in an animal room at $22 \pm 3^{\circ} \mathrm{C}$, relative humidity of $50 \pm 6 \%$, an inverse 12:12 hour light/dark cycle. Rats had free access to standard rat chow (Pars Co., Tehran) and tap water during the study. All experimental procedures and rat care and handling were performed in accordance with guidelines provided by the local ethics committee of the Research Institute for Endocrine Sciences, Shahid Beheshti University of Medical Sciences.

Animals were anesthetized by intraperitoneal injection of ketamine/xylazine (50 $\mathrm{mg} / \mathrm{kg}$ and $10 \mathrm{mg} / \mathrm{kg}$ ) and the abdomen was exposed, and $0.5 \mathrm{mg} / \mathrm{mL}$ of collagenase $\mathrm{P}$ (Roche, Cat. \# 1213, Germany) in $10 \mathrm{~mL}$ cold Hanks' balanced salt solution (HBSS) $[\mathrm{pH}=7.4$; containing $\mathrm{KCl}, 5.36$; $\mathrm{CaCl}_{2}, 1.26 ; \mathrm{NaCl}, 136 ; \mathrm{MgSO}_{4} 7 \mathrm{H}_{2} \mathrm{O}, 0.8 ; \mathrm{Na}_{2} \mathrm{HPO}_{4} 2 \mathrm{H}_{2} \mathrm{O}$, $0.33 ; \mathrm{NaHCO}_{3}, 4.16 ; \mathrm{KH}_{2} \mathrm{PO}_{4}, 0.44$ ) all in mM (Merck, Germany) and gassed with $95 \% \mathrm{O}_{2}, 5 \% \mathrm{CO}_{2}$ for five minutes at the beginning] was injected into the common bile duct; the expanded pancreas was detached, transmitted to a $50 \mathrm{~mL}$ falcon container and placed in a water bath $\left(37^{\circ} \mathrm{C}\right)$ for 15 minutes. At the end of digestion, $30 \mathrm{~mL}$ cold HBSS was added and the tube was shaken for one minute. Tube contents were filtered through a $500 \mu \mathrm{m}$ plastic mesh to discard any undigested tissue. After three washes with cold HBSS, islets were selected under a stereomicroscope (Kyowa, SDZ-TR-PL Japan); a group of 10 islets were incubated in a cell strainer containing $4 \mathrm{~mL}$ of RPMI 1640 medium containing $10 \%$ fetal bovine serum and $1 \%$ of penicillin/streptomycin $(17,18)$. Insulin release was assessed in response to vitamin D (D1530, Sigma) following 24 and 48 hours coincubation of islets with vitamin $\mathrm{D}(0.1,1$, and 10 $\mathrm{nM}$ ) and glucose (5.6,11.1 and 16.7 mM).

In addition, islets were preincubated with vitamin $D$ for 24 and 48 hours and glucose-stimulated insulin secretion (GSIS) was assessed for one hour in the presence of 5.6 and $16.7 \mathrm{mM}$ glucose. For in vitro assessment of insulin secretion, batches of eight islets were transferred into 1.5 $\mathrm{mL}$ plastic cups, and $1 \mathrm{~mL}$ of Krebs Ringer solution [ $(\mathrm{pH}=$ 7.4); $\mathrm{NaCl}, 115 ; \mathrm{KCl}, 5 ; \mathrm{MgCl}_{2} 6 \mathrm{H}_{2} \mathrm{O}, 1 ; \mathrm{CaCl}_{2}$, 2.5; $\mathrm{NaHCO}_{3}$, 24 (Merck, Germany); HEPES, 16 (Sigma, USA) all in mM] and $5 \mathrm{~g} / \mathrm{dL}$ BSA (Fluka, USA) with different glucose concentrations (5.6 and $16.7 \mathrm{mM}$ ) were added into the cups, incubated for 60 minutes in $37^{\circ} \mathrm{C}$ water bath and gassed with $95 \% \mathrm{O}_{2}, 5 \% \mathrm{CO}_{2}$ for five minutes at the beginning. Aliquots of supernatant were collected and stored at $-20^{\circ} \mathrm{C}$ for insulin determination. Insulin concentration was measured by ELISA technique (Mercodia, Sweden). Intra and inter-assay coefficients of variations for insulin measurements were $6.1 \%$ and $9.7 \%$, respectively.

\subsection{Statistical Analysis}

All data were expressed as mean \pm SEM and analyzed us- ing GraphPad Prism software (Version 5.00 for Windows, GraphPad Software, San Diego California USA). Two-way analysis of variance (ANOVA) and Bonferroni post-hoc test were used to compare serum insulin concentrations in different levels of glucose and vitamin D. P value below 0.05 was considered statistically significant.

Figure 1. Insulin Release in Response to Incubation With Different Concentrations of Vitamin D

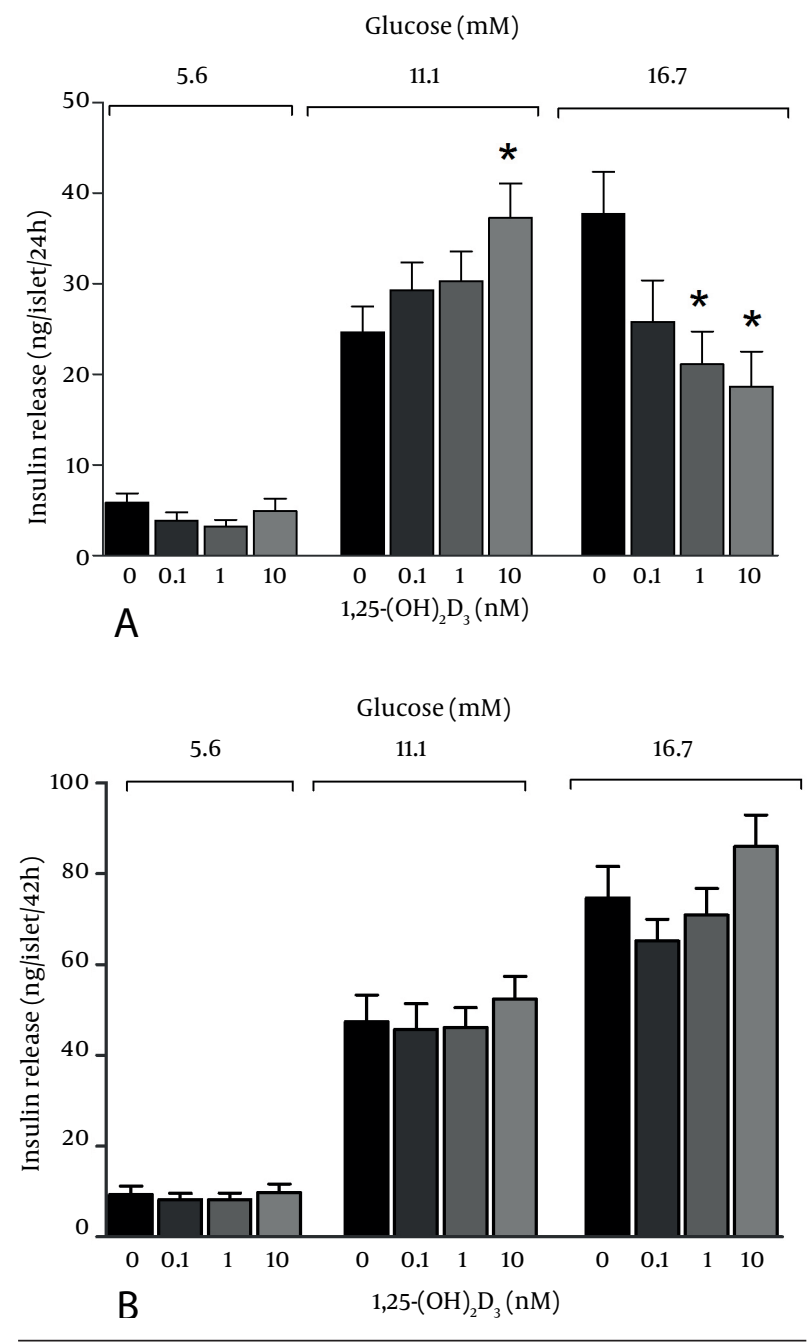

Insulin release in response to 24-hours (A) and 48-hours (B) incubation with different concentrations of vitamin $D$ in presence of 5.6,11.1, and 16.7 mM Glucose. *: $\mathrm{P}<0.05$ compared to control (vitamin $\mathrm{D}=0$ ).

\section{Results}

Effects of coincubation of vitamin D with glucose on insulin release from islets were shown in Figure 1. As shown, coincubation of islets with $10 \mathrm{nM}$ of vitamin D and $11.1 \mathrm{mM}$ glucose increased insulin release, while 1 and $10 \mathrm{nM}$ vitamin D with $16.7 \mathrm{mM}$ glucose decreased insulin release. Vitamin D had no effect on insulin release from islets during 24 hours coincubation with $5.6 \mathrm{mM}$ glucose or 48 hours Coincubation with 5.6, 11.1, and $16.7 \mathrm{mM}$ glucose. Effects of 5.6 and $16.7 \mathrm{mM}$ glucose on GSIS in islets, 
following 24 and 48 hours preincubation with vitamin D were shown in Figure 2. As seen, 24 and 48 hours preincubation with $10 \mathrm{nM}$ of vitamin $\mathrm{D}$ and 48 hours preincubation with 1 and $10 \mathrm{nM}$ of vitamin D increased GSIS in the presence of $16.7 \mathrm{mM}$ glucose. No significant changes were detected in response to $5.6 \mathrm{mM}$ glucose.

Figure 2. Insulin Release in Response to Glucose
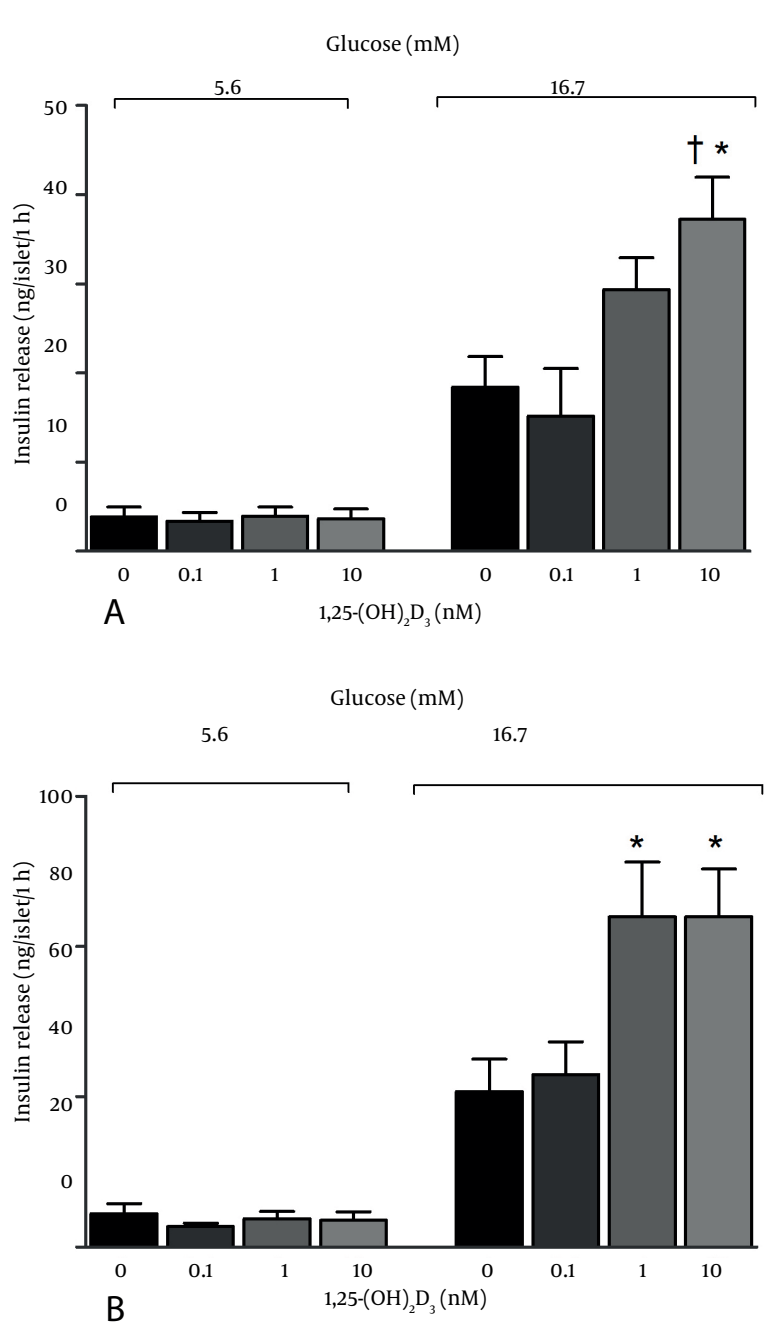

Insulin release in response to 5.6 and $16.7 \mathrm{mM}$ glucose for a duration of one hour in islets from normal rats following 24-houes (A) and 48-hours (B) preincubation with vitamin D. *: P $<0.05$ compared to control (vita$\min \mathrm{D}=0) ; \uparrow: \mathrm{P}<0.05$ compared to vitamin $\mathrm{D} 1 \mathrm{nM}$.

\section{Discussion}

Preincubation of vitamin D with glucose for 24 or 48 hours increased GSIS from islets only at high doses of vitamin D and glucose. In addition, when vitamin $\mathrm{D}$ and glucose were coincubated for 24 hours, insulin release was increased with $10 \mathrm{nM}$ vitamin $\mathrm{D}$ and $11.1 \mathrm{mM}$ glucose; whereas, insulin release decreased with 1 and $10 \mathrm{nM}$ vitamin D and 16.7 glucose. These results were consistent with those studies reporting an association between vitamin D and insulin release from cells (19-21).
Preincubation with vitamin D increased GSIS in response to $16.7 \mathrm{mM}$ glucose, findings in agreement with the results of Billaudel et al. who reported that GSIS is eliminated by vitamin D deficiency in rats; however, six hours preincubation with 0.001-1000 nM vitamin D had a stimulatory effect on GSIS in response to $8.3 \mathrm{mM}$ glucose (8). Furthermore, it has been reported that 24 hours preincubation with $10 \mathrm{nM}$ vitamin D increases GSIS in the presence of $8.3 \mathrm{mM}$ glucose in vitamin D-deficient rats (22). Tanaka et al. have also reported that insulin secretion induced by $16.7 \mathrm{mM}$ glucose in vitamin $\mathrm{D}$ deficient rats was only $35 \%$ of that of control rats, but was restored to that of the controls in vitamin D-treated rats (23). Bourlon et al. have also reported that insulin secretion is destroyed in vitamin $\mathrm{D}$ deficient rats and restored by $1,25-(\mathrm{OH})_{2} \mathrm{D}_{3}(24)$.

Results of this study showed that vitamin D affects insulin secretion only in the presence of high glucose level, whereas it does not affect insulin secretion in presence of 5.6 mM glucose. Vitamin D enhances sensitivity of cells to glucose, and has been suggested that the effect of vitamin D on insulin secretion may be ATP-dependent $(4,22)$. Consistent with our results, d'Emden et al. have shown that coincubation of $0.1 \mathrm{nM}$ and $1 \mathrm{nM}$ vitamin $\mathrm{D}$ with 10 $\mathrm{mM}$ glucose did not increase insulin release in medium for up to 180 hours (25). Faure et al. have confirmed that coincubation of $0.001 \mathrm{nM}$ vitamin D with $8.3 \mathrm{mM}$ glucose did not affect insulin secretion (22). Chan et al. have reported that in vitro addition of vitamin D had no effect on insulin secretion from normal or vitamin $\mathrm{D}$ deficient rats (26). In addition, two human studies found no change in insulin release following vitamin D supplementation in adults with either obesity or insulin resistance (1921). Contradictory to our results, Billaudel et al. have reported that coincubation of 0.001-1000 nM of vitamin D with $8.3 \mathrm{mM}$ glucose had an incremental dose-dependent effect on insulin secretion (8). Moreover, d'Emden et al. Have demonstrated that coincubation of $10 \mathrm{nM}$ vitamin D with $10 \mathrm{mM}$ glucose increased insulin secretion 2.5 fold in a cell medium (25).

To date, no study has investigated the effect of vitamin D on insulin secretion in the presence of $16.7 \mathrm{mM}$ glucose in short duration (up to 24 hours). Lower insulin secretion has been reported in the presence of high glucose concentrations compared to low glucose concentrations in cell medium. In addition, high glucose concentrations significantly decrease insulin secretion in cultured

cells; these data indicates that exposure to high glucose levels induces a glucotoxic situation, which could impair insulin secretion in response to glucose (16). Contrary to the finding of our study, d'Emden et al. have demonstrated that coincubation of $10 \mathrm{nM}$ vitamin D with $20 \mathrm{mM}$ glucose increased insulin secretion in a cell medium (25), but suggested a significantly increased insulin release in islets following 96 hours coincubation or longer.

The exact mechanisms of vitamin D effect on insulin secretion in the presence of glucose are not yet fully 
understood and need further studies, but it has been suggested that vitamin D directly increases insulin secretion in cells (25). Faure et al. have reported that vitamin D enhances $\mathrm{Ca}^{2+}$ entry or $\mathrm{Ca}^{2+}$ mobilization in cells, which could amplify insulin secretion in the presence of glucose (22). Also Bourlon et al. have also shown that vitamin $D$ requires a delay to increase insulin secretion from cells; this delay varies from 6 hours pre-incubation in vitro, 3 hours to 20 hours in vivo and 48 hours in culture, which can indicates the genomic effects of vitamin D (9).

In conclusion, effects of coincubation of islets with vitamin D and glucose depend on glucose concentration. Vitamin D significantly decreased insulin secretion in the presence of $16.7 \mathrm{mM}$ glucose, but increased insulin secretion in the presence of $11.1 \mathrm{mM}$ glucose. In addition, this study showed that preincubation of islets with vitamin D increased GSIS at high levels of glucose (16.7 mM), while no effect was observed at low levels.

\section{Acknowledgements}

The authors wish to thank Ms. N. Shiva for critical editing for English grammar and syntax of the manuscript.

\section{Authors' Contributions}

Asghar Ghasemi contributed substantially to conception and design, analysis and interpretation of data, drafting of the manuscript and revised and approved the final version for publication. Leila Syedmoradi performed data collection and laboratory tests and contributed substantially to analysis and interpretation of data. Fatemeh Bageripour contributed substantially to design, analysis and interpretation of data. Sajad Jeddi drafted the manuscript.

\section{Funding/Support}

This work was supported by the project (No. 257) of Research Institute for Endocrine Sciences, Shahid Beheshti University of Medical Sciences, Tehran, Iran.

\section{References}

1. Maria Rotella C, Pala L, Mannucci E. Role of insulin in the type 2 diabetes therapy: past, present and future. Int J Endocrinol Metab. 2013;11(3):137-44

2. Ghasemi A, Zahediasl S. Potential therapeutic effects of nitrate/ nitrite and type 2 diabetes mellitus. Int J Endocrinol Metab. 2013;11(2):63-4.

3. Alvarez JA, Ashraf A. Role of vitamin d in insulin secretion and insulin sensitivity for glucose homeostasis. Int $J$ Endocrinol. 2010;2010:351385.

4. Bourlon PM, Faure-Dussert A, Billaudel B. Modulatory role of 1,25 dihydroxyvitamin D3 on pancreatic islet insulin release via the cyclic AMP pathway in the rat. BrJPharmacol.1997;121(4):751-8.

5. Riachy R, Vandewalle B, Kerr Conte J, Moerman E, Sacchetti P, Lukowiak B, et al. 1,25-dihydroxyvitamin D3 protects RINm5F and human islet cells against cytokine-induced apoptosis: implication of the antiapoptotic protein A20. Endocrinology. 2002;143(12):4809-19.
6. Mathieu C, Gysemans C, Giulietti A, Bouillon R. Vitamin D and diabetes. Diabetologia. 2005;48(7):1247-57.

7. Palomer X, Gonzalez-Clemente JM, Blanco-Vaca F, Mauricio D. Role of vitamin $\mathrm{D}$ in the pathogenesis of type 2 diabetes mellitus. Diabetes Obes Metab. 2008;10(3):185-97.

8. Billaudel BJ, Faure AG, Sutter BC. Effect of 1,25 dihydroxyvitamin D3 on isolated islets from vitamin D3-deprived rats. Am J Physiol. 1990;258(4 Pt 1):E643-8.

9. Bourlon PM, Billaudel B, Faure-Dussert A. Influence of vitamin D3 deficiency and 1,25 dihydroxyvitamin D3 on de novo insulin biosynthesis in the islets of the rat endocrine pancreas.J Endocrinol. 1999;160(1):87-95.

10. Cade C, Norman AW. Rapid normalization/stimulation by 1,25-dihydroxyvitamin D3 of insulin secretion and glucose tolerance in the vitamin D-deficient rat. Endocrinology. 1987;120(4):1490-7.

11. Dalgard C, Petersen MS, Weihe P, Grandjean P. Vitamin D status in relation to glucose metabolism and type 2 diabetes in septuagenarians. Diabetes Care. 2011;34(6):1284-8.

12. Zittermann A. Vitamin D and disease prevention with special reference to cardiovascular disease. Prog Biophys Mol Biol. 2006;92(1):39-48.

13. Holick MF. Vitamin D deficiency. N Engl J Med. 2007;357(3):266-81.

14. Zeitz U, Weber K, Soegiarto DW, Wolf E, Balling R, Erben RG. Impaired insulin secretory capacity in mice lacking a functional vitamin D receptor. FASEB J. 2003;17(3):509-11.

15. Nikooyeh B, Neyestani TR, Farvid M, Alavi-Majd H, Houshiarrad A, Kalayi A, et al. Daily consumption of vitamin D- or vitamin D + calcium-fortified yogurt drink improved glycemic control in patients with type 2 diabetes: a randomized clinical trial. Am J Clin Nutr. 2011;93(4):764-71.

16. Krus U, Kotova O, Spegel P, Hallgard E, Sharoyko VV, Vedin A, et al. Pyruvate dehydrogenase kinase 1 controls mitochondrial metabolism and insulin secretion in INS-1 832/13 clonal beta-cells. Biochem J. 2010;429(1):205-13.

17. Farahani H, Ghasemi A, Roghani M, Zahediasl S. The effect of maternal hypothyroidism on the carbohydrate metabolism and insulin secretion of isolated islets in adult male offspring of rats. Horm Metab Res. 2010;42(11):792-7.

18. Mahmoodzadeh Sagheb M, Azarpira N, Yaghobi R. The Effect of Leptin and Adiponectin on KiSS-1 and KissR mRNA Expression in Rat Islets of Langerhans and CRI-D2 Cell Line. Int J Endocrinol Metab. 2014;12(2).

19. von Hurst PR, Stonehouse W, Coad J. Vitamin D supplementation reduces insulin resistance in South Asian women living in New Zealand who are insulin resistant and vitamin D deficient - $\mathrm{a}$ randomised, placebo-controlled trial. BrJ Nutr. 2010;103(4):549-55.

20. Nagpal J, Pande JN, Bhartia A. A double-blind, randomized, placebo-controlled trial of the short-term effect of vitamin D3 supplementation on insulin sensitivity in apparently healthy, middleaged, centrally obese men. Diabet Med. 2009;26(1):19-27.

21. Kayaniyil S, Vieth R, Retnakaran R, Knight JA, Qi Y, Gerstein HC, et al. Association of vitamin D with insulin resistance and beta-cell dysfunction in subjects at risk for type 2 diabetes. Diabetes Care. 2010;33(6):1379-81.

22. Faure A, Sutter BC, Billaudel B. Is 1,25-dihydroxyvitamin D3 the specific vitamin D3 metabolite active on insulin release and calcium handling by islets from vitamin D3-deprived rats? Diabete Metab.1991;17(2):271-8

23. Tanaka Y, Seino Y, Ishida M, Yamaoka K, Yabuuchi H, Ishida H, et al. Effect of vitamin D3 on the pancreatic secretion of insulin and somatostatin. Acta Endocrinol (Copenh). 1984;105(4):528-33.

24. Bourlon PM, Faure-Dussert A, Billaudel B, Sutter BC, Tramu G, Thomasset M. Relationship between calbindin-D28K levels in the A and B cells of the rat endocrine pancreas and the secretion of insulin and glucagon: influence of vitamin D3 deficiency and 1,25-dihydroxyvitamin D3. J Endocrinol.1996;148(2):223-32.

25. d'Emden MC, Dunlop M, Larkins RG, Wark JD. The in vitro effect of 1 alpha,25-dihydroxyvitamin D3 on insulin production by neonatal rat islets. Biochem Biophys Res Commun. 1989;164(1):413-8.

26. chan JC, Rogers KS. Lack of influence of vitamin D deficiency on insulin release from the isolated pancreatic islets of rats. Experientia. 1986;42(11-12):1253-4. 